\title{
THREE-COMPONENT CARBON-CARBON BOND-FORMING REACTIONS FOR THE SYNTHESIS OF $\beta$-AMINO CARBONYL COMPOUNDS USING MALEIC ACID-CATALYZED ONE-POT MANNICH-TYPE REACTION IN ETHANOL
}

\author{
Malek Taher Maghsoodlou*1, Seyyed Rasul Mousavi², Ali Roygar', Mojtaba Lashkari \\ ${ }^{1}$ Department of Chemistry, Faculty of Science, University of Sistan and Baluchestan, \\ P.O. Box 98135-674, Zahedan, Iran \\ ${ }^{2}$ Young Researchers and Elites club, Science and Research Branch, \\ Islamic Azad University, Tehran, Iran \\ ${ }^{3}$ Faculty of Science, Velayat University, Iranshahr, Iran \\ *Corresponding author; E-mail: mt_maghsoodlou@chem.usb.ac.ir
}

(Received July 7, 2017; Accepted August 28, 2017)

\begin{abstract}
Herein, we described a one-pot, three-component and environmentally benign method for the synthesis of $\beta$-amino ketones based on the reaction of acetophenones, aromatic aldehydes, and aromatic amines using maleic acid as a green catalyst in ethanol as green solvent. The present methodology offers several advantages including good yields, mild reaction conditions and an inexpensive catalyst with a very easy work up. In addition, this method excludes the use of volatile organic solvents, tedious workup and column chromatographic purification of compounds, making the method greener, convenient and superior. All new compounds were well characterized by IR, ${ }^{1} \mathrm{H}$ and ${ }^{13} \mathrm{C}$ NMR spectroscopy and physical data.
\end{abstract}

Keywords: three-component, maleic acid, Mannich reaction, one-pot, $\beta$-amino ketone, homogeneous catalyst.

\section{INTRODUCTION}

Carl Mannich first recognized the enormous significance of aminoalkylation of $\mathrm{CH}$ acidic compounds, and then he extended the chemistry into a broad based synthetic procedure through systematic research (AREND et al., 1998). Mannich reaction is one of the most important $\mathrm{C}-\mathrm{C}$ bond forming reactions in organic synthesis for the preparation of secondary, tertiary amine derivatives and very useful compounds as building blocks in the synthesis of pharmaceuticals and natural products (KOBAYASHI and ISHITANI, 1999; IDHAYADHULLA et al., 2011). The Mannich reaction is an important procedure for synthesizing of $\beta$-amino carbonyl compounds, which are significant synthetic intermediates for various pharmaceuticals and natural products (LOH et al., 2000). The development of catalyst for synthetic methods has become an important research area, aiming to make the syntheses simpler, to save energy and to prevent toxicity in chemical processes. In recent years, the search for environmentally benign chemical processes or methodologies has received much attention (CHOUDHARY et al., 
2006; KURESHY et al., 2010; MouSAVi et al., 2014; MouSAVI et al., 2015). Therefore, in chemistry "ideal synthesis" has been defined as one in which the target compound is generated in one step, in efficiency yield, from readily available and inexpensive starting materials in a resource-effective and environmentally acceptable process (SANDAROOS and DAMAVANDI, 2013). Hence, multi-component reactions (MCRs) have received much attention in the field of synthetic organic chemistry as well as medicinal chemistry, because the strategies of MCR offer significant advantages over conventional synthetic procedures (MADDILA et al., 2016; AHMADI et al., 2017). Therefore, projecting reactions in pursuit multibond formation in one operation is becoming one of the leading challenges in the field of green organic synthesis (MOUSAVI et al., 2014). The approach of MCRs delivers numbers of advantages over conventional transformations, such as shorter reaction times, higher product yields, lower costs, an easy work-up process, and environmental being ( MADDILA et al., 2016D'SOUZA and MUELLER, 2007).

Organocatalysis has long existed as part of organic chemistry such as, acid or amine catalyzed Michael-additions, aldol condensation or Knoevenagel reactions ( RANJBAR-KARIMI et al., 2011; Mousavi and MaghSOOdlou, 2014; Mousavi et al., 2015; Mousavi and MAGHSOODLOU, 2015). Over the past decades, an extremely high output of results of different organocatalyzed reactions and transformations was heeded. Because, these transformations provide an extremely mild, selective access and operationally simple to required defined configured building blocks or natural products. Specifically, these include Mannich reactions, cycloadditions, aldol additions, conjugate additions etc (DöMLING and UGI, 2000; MAHRWALD, 2013; SCHEFFLER and MAHRWALD, 2013;).

As noted above, $\beta$-amino carbonyl compounds are the main products of Mannich reaction and its derivatives are used for synthesizing peptides, amino alcohols, lactams and as precursors to optically active amino acids (HowARD et al., 2006). $\beta$-Amino carbonyl compounds forming via Mannich reaction are considerable and very important intermediates in the synthesis of natural products and pharmaceuticals (KOBAYASHI and ISHITANI, 1999; MüLLER et al., 1999; GUO et al., 2007). Therefore, much attention has been drawn to the development of new synthetic methods to prepare these compounds. Traditionally, Mannich reactions have been achieved by using proton acids or Lewis acids as catalysts (LOH et al., 2000; Notz et al., 2001; KoBAYASHI and MANABE, 2002; WANG et al., 2005; TERADA et al., 2006; PHUKAN et al., 2006; SAHOO et al., 2006; YI and CAI, 2006; WANG et al., 2007; Li et al., 2007; WU et al., 2007; KIDWAI et al., 2009; YUE et al., 2009; KURESHY et al., 2010; SHARMA et al., 2012; WANG et al., 2012; ZHANG et al., 2012; SAADATJOO et al., 2017). However, despite recent spectacular advances, these procedures are not entirely satisfactory and suffer from some limitations including use of toxic reagents, atmosphere sensitive reagents or catalysts, a large amount of expensive and non-recoverable catalyst, requirement of special effort for catalyst preparation. Nevertheless, there is still a need for further efficient and, in particular, technically feasible methods in this field.

In continuation of our previous research toward the improvement of new green and convenient routes for the synthesis of various compounds using homogeneous catalysts (RANJBAR-KARIMI et al., 2011; MousAVI et al., 2013; MOUSAVI and MAGHSOODLOU, 2014; MOUSAVI et al., 2014; MAGHSOODLOU et al., 2015; MOUSAVI et al., 2015), we report herein, the application of maleic acid as a homogeneous catalyst under mild conditions for efficient, convenient and facile green synthesis of various $\beta$-amino carbonyl derivatives through the one-pot, three-component reaction of aldehydes, amines and acetophenone in ethanol at room temperature. In addition, to the best of our knowledge, there are no reports on the use of maleic acid as a homogeneous catalyst for this conversion (Scheme 1). 


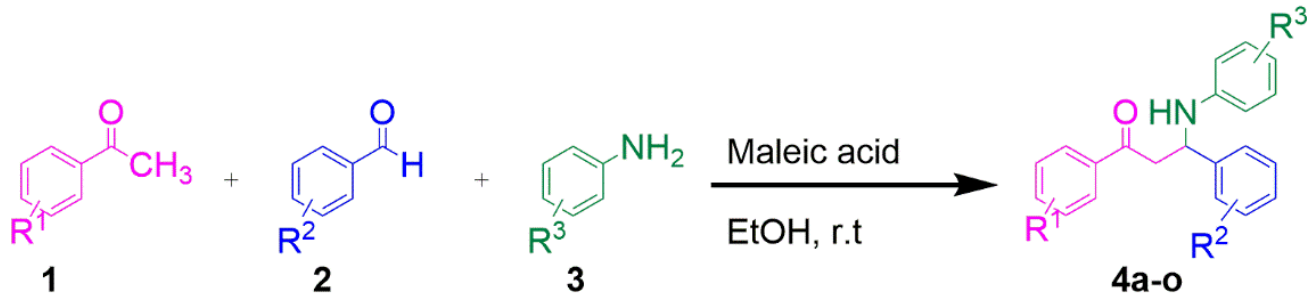

Scheme 1. Synthesis of $\beta$-amino carbonyl derivatives.

As shown in Fig. 1, maleic acid is one of the isomers of butenedioic acid was used as an efficient, green and natural catalyst in this work for synthesizing $\beta$-amino ketones. In maleic acid the carboxylic acid groups are cis.<smiles>OOc1ccc(O)o1</smiles>

Figure 1. The structure of maleic acid.

\section{MATERIALS AND METHODS}

\section{General}

Melting point and IR spectra of all compounds were obtained on an Electrothermal 9100 apparatus and a JASCO FT/IR-460 plus spectrometer, respectively. ${ }^{1} \mathrm{H}$ and ${ }^{13} \mathrm{C}$ NMR spectra of the new compounds were recorded on a Bruker DRX-400 Avance instrument in $\mathrm{CDCl}_{3}$ as the solvent with TMS as internal standard at 400 and $100 \mathrm{MHz}$ respectively. Elemental analyses for $\mathrm{C}, \mathrm{H}$, and $\mathrm{N}$ for the new compounds were performed using a Heraeus CHN-O-Rapid analyzer. All reagents were purchased from Merck (Darmastadt, Germany), Acros (Geel, Belgium) and Fluka (Buchs, Switzerland), and use without further purification.

\section{General procedure for the synthesis of compounds 4}

To a mixture of acetephenone $\mathbf{1}$ ( $1 \mathrm{mmol})$, aldehyde $\mathbf{2}(1 \mathrm{mmol})$ and amine $\mathbf{3}$ (1 mmol) in ethanol, $25 \mathrm{~mol} \%$ maleic acid was added. The mixture was stirred at room temperature for an appropriate time (Table 4). The progress of the reaction was followed by thin-layer chromatography (TLC). After completion of the reaction, the precipitate was separated by simple filtration, and washed with ethanol $(2 \times 3 \mathrm{~mL})$ and dried in the air to afford the title pure compounds. The identity of the known products was confirmed by comparison of their spectroscopic data and physical properties with those available in published articles. The novel products were identified by spectral data (i.e., IR, ${ }^{1} \mathrm{H}-\mathrm{NMR},{ }^{13} \mathrm{C}-\mathrm{NMR}$ and $\mathrm{CHN}$ ). The spectral data of the novel compounds as well as some representative compounds are described below.

3-((4-Chlorophenyl)amino)-3-(3-methoxyphenyl)-1-phenylpropan-1-one (4n)

White solid (59\%), m.p. 155.5-156.5 ${ }^{\circ} \mathrm{C}$; IR $\left(\mathrm{KBr}, v_{\max } / \mathrm{cm}^{-1}\right): 3383,1669,1603,808$. ${ }^{1} \mathrm{H}$ NMR $\left(400 \mathrm{MHz}, \mathrm{CDCl}_{3}, \delta / \mathrm{ppm}\right): \delta=3.40(\mathrm{dd}, J=16.4,7.6 \mathrm{~Hz}, 1 \mathrm{H}, \mathrm{H}-2), 3.49$ (dd, $J=$ 16.4, $5.2 \mathrm{~Hz}, 1 \mathrm{H}, \mathrm{H}-2), 3.97$ (s, 3H, $\mathrm{OCH}_{3}$ ), 4.59 (br s, 1H, NH), 4.92 (t, J = 5.6 Hz, 1H, H3), $6.49(\mathrm{~d}, J=8.8 \mathrm{~Hz}, 2 \mathrm{H}, \mathrm{Ar}-\mathrm{H}), 6.87(\mathrm{~d}, J=8.8 \mathrm{~Hz}, 2 \mathrm{H}, \mathrm{Ar}-\mathrm{H}), 7.04(\mathrm{~d}, J=8.8 \mathrm{~Hz}, 2 \mathrm{H}$, Ar-H), $7.34(\mathrm{~d}, J=8.4 \mathrm{~Hz}, 2 \mathrm{H}, \mathrm{Ar}-\mathrm{H}), 7.46(\mathrm{t}, J=7.6 \mathrm{~Hz}, 2 \mathrm{H}, \mathrm{Ar}-\mathrm{H}), 7.58(\mathrm{t}, J=7.6 \mathrm{~Hz}, 1 \mathrm{H}$, Ar-H), 7.92 (d, $J=7.2 \mathrm{~Hz}, 2 \mathrm{H}, \mathrm{Ar}-\mathrm{H}) .{ }^{13} \mathrm{C} \mathrm{NMR}\left(100 \mathrm{MHz}, \mathrm{CDCl}_{3}, \delta / \mathrm{ppm}\right): \delta=46.2,54.3$, 
55.2, 114.2, 114.9, 122.3, 127.3, 128.1, 128.7, 133.5, 134.3, 145.3, 197.5. Anal. Calcd for $\mathrm{C}_{22} \mathrm{H}_{20} \mathrm{ClNO}_{2}: \mathrm{C}, 72.23 ; \mathrm{H}, 5.51 ; \mathrm{N}, 3.83$. Found: C, 72.35; H, 5.58; N, 3.89.

3-((4-Bromophenyl)amino)-3-(3-methoxyphenyl)-1-(p-tolyl)propan-1-one (4o)

White solid (45\%), m.p. $151-152{ }^{\circ} \mathrm{C}$; IR (KBr, $\left.v_{\max } / \mathrm{cm}^{-1}\right): 3380,1665,1651,503 .{ }^{1} \mathrm{H}$ NMR (400 MHz, $\left.\mathrm{CDCl}_{3}, \delta / \mathrm{ppm}\right): \delta=2.42\left(\mathrm{~s}, 3 \mathrm{H}, \mathrm{CH}_{3}\right), 3.36(\mathrm{dd}, J=16.0,7.6 \mathrm{~Hz}, 1 \mathrm{H}, \mathrm{H}-$ 2), 3.45 (dd, $\left.J=16.0,5.2 \mathrm{~Hz}, 1 \mathrm{H}, \mathrm{H}^{\prime}-2\right), 3.97$ (s, 3H, $\left.\mathrm{OCH}_{3}\right), 4.63$ (br s, $\left.1 \mathrm{H}, \mathrm{NH}\right), 4.89$ (dd, $J$ $=7.2,5.2 \mathrm{~Hz}, 1 \mathrm{H}, \mathrm{H}-3), 6.44(\mathrm{~d}, J=8.8 \mathrm{~Hz}, 2 \mathrm{H}, \mathrm{Ar}-\mathrm{H}), 6.87(\mathrm{~d}, J=8.8 \mathrm{~Hz}, 2 \mathrm{H}, \mathrm{Ar}-\mathrm{H}), 7.16$ $(\mathrm{d}, J=8.8 \mathrm{~Hz}, 2 \mathrm{H}, \mathrm{Ar}-\mathrm{H}), 7.26(\mathrm{~d}, J=8.0 \mathrm{~Hz}, 2 \mathrm{H}, \mathrm{Ar}-\mathrm{H}), 7.33(\mathrm{~d}, J=8.8 \mathrm{~Hz}, 2 \mathrm{H}, \mathrm{Ar}-\mathrm{H}), 7.82$ (d, $J=8.4 \mathrm{~Hz}, 2 \mathrm{H}, \mathrm{Ar}-\mathrm{H}) .{ }^{13} \mathrm{C}$ NMR $\left(100 \mathrm{MHz}, \mathrm{CDCl}_{3}, \delta / \mathrm{ppm}\right): \delta=21.6,46.1,54.3,55.2$, $109.4,114.2,115.4,127.3,128.3,129.4,131.7,134.1,134.4,144.4,146.0,158.8,197.9$. Anal. Calcd for $\mathrm{C}_{23} \mathrm{H}_{22} \mathrm{BrNO}_{2}$ : C, 65.10; H, 5.23; N, 3.30. Found: C, 65.23; H, 5.34; N, 3.37.

\section{RESULTS AND DISCUSSION}

Initially, we conducted the three-component reaction of acetophenone, benzaldehyde and aniline in the presence of varying amounts of maleic acid as catalyst in ethanol at ambient temperature conditions. The corresponding $\beta$-amino ketone was synthesized. The results were summarized in Table 1 and showed that the reaction using $25 \mathrm{~mol} \%$ maleic acid at room temperature proceeded in highest yield (entry 4, Table 1). As shown in Table 1 when the reaction was performed in the absence of maleic acid, the reaction did not progress even after $48 \mathrm{~h}$ (entry 8).

Table 1. Reaction optimization for the synthesis of product $\mathbf{4} \mathbf{b} .^{a}$

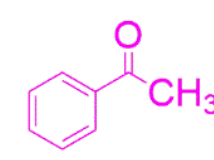

1

\begin{tabular}{cr}
\hline Entry & Cataly \\
\hline 1 & 1 \\
2 & 15 \\
3 & 2 \\
4 & 25 \\
5 & 3 \\
6 & 3 \\
7 & 4 \\
8 & -
\end{tabular}
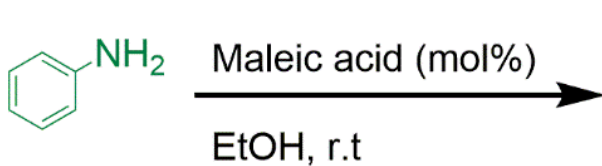

3

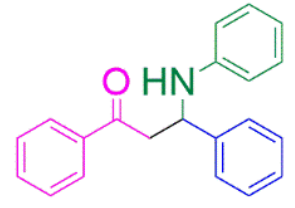

4b

Time (h) $\quad$ Yield (\%)

${ }^{\mathrm{a}}$ The reaction was carried out using acetophenone $(1 \mathrm{mmol})$, benzaldehyde $(1 \mathrm{mmol})$ and aniline $(2$ $\mathrm{mmol})$ in $\mathrm{EtOH}(5 \mathrm{~mL})$ at room temperature.

${ }^{\mathrm{b}}$ Yield refers to the pure isolated product.

Next, to optimize the reaction temperature, the reaction of acetophenone, benzaldehyde and aniline was studied in the presence of $25 \mathrm{~mol} \%$ maleic acid in $\mathrm{EtOH}$ at different temperatures. The results were summarized in Table 2 and showed that the reaction using $25 \mathrm{~mol} \%$ maleic acid at room temperature proceeded in highest yield (entry 1, Table 2). Also as can be seen in Table 2, at the higher temperature did not increase the reaction yield (entries 2-4, Table 2). 
Table 2. Effect of different temperatures on the model reaction. ${ }^{\mathrm{a}}$

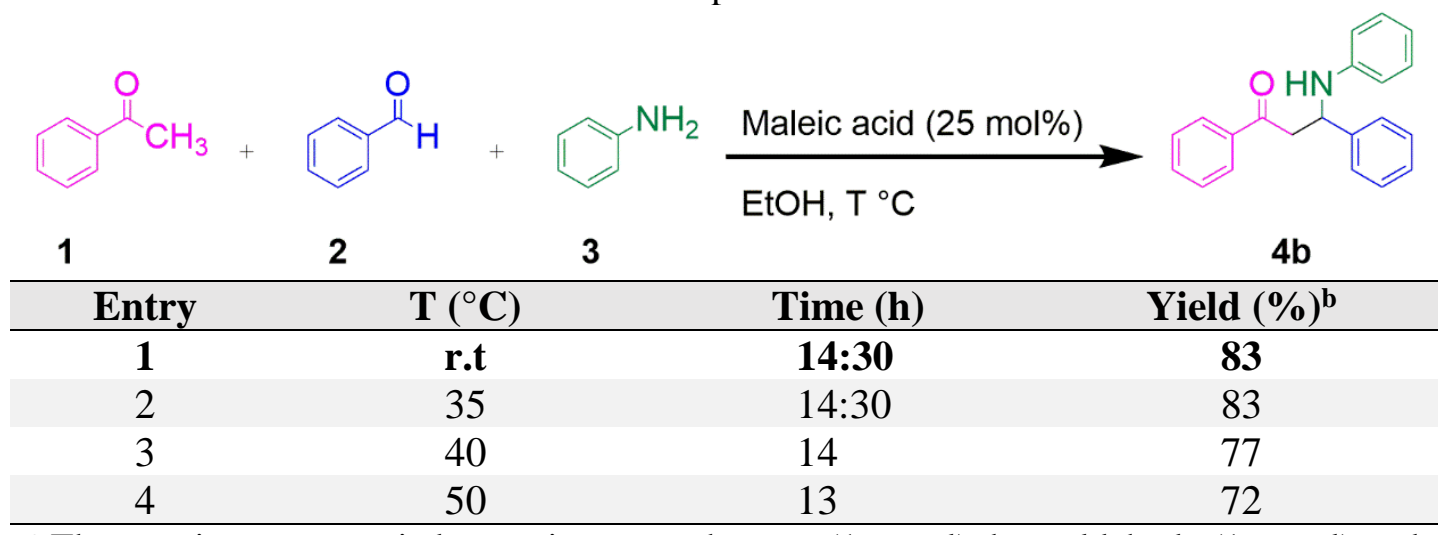

${ }^{a}$ The reaction were carried out using acetophenone $(1 \mathrm{mmol})$, benzaldehyde $(1 \mathrm{mmol})$ and aniline $(1 \mathrm{mmol})$ in the presence of $25 \mathrm{~mol} \%$ maleic acid in $\mathrm{EtOH}(5 \mathrm{~mL})$ at different temperatures.

${ }^{\mathrm{b}}$ Yield refers to the pure isolated products.

In the next step, the effect of different solvents on the model reaction was investigated at room temperature using $25 \mathrm{~mol} \%$ of the catalyst. Various solvents like water, ethanol and the mixture of different ratio of ethanol/water, methanol and chloroform were screened to test the efficiency of our catalyst and the results are summarized in Table 3 . The reaction in water and the ratio EtOH/ $/ \mathrm{H}_{2} \mathrm{O}$ (1:2) could not proceed to completion even after $72 \mathrm{~h}$ (entries 1 and 5 , Table 3), chloroform as a solvent could not produce satisfactory results (entry 7, Table 3), using methanol, EtOH/ $\mathrm{H}_{2} \mathrm{O}(2: 1)$ and $\mathrm{EtOH} / \mathrm{H}_{2} \mathrm{O}(1: 1)$ as solvents gave average results with moderate product yield (entries 3, 4 ad 6, Table 3). As shown in Table 3, among the tested solvents, ethanol was found to be most efficient with excellent product yield in 14:30 h.

Table 3. Initial solvent effect studies for synthesis of $\beta$-amino ketone derivatives with 25 mol\% catalyst at ambient conditions. ${ }^{a}$

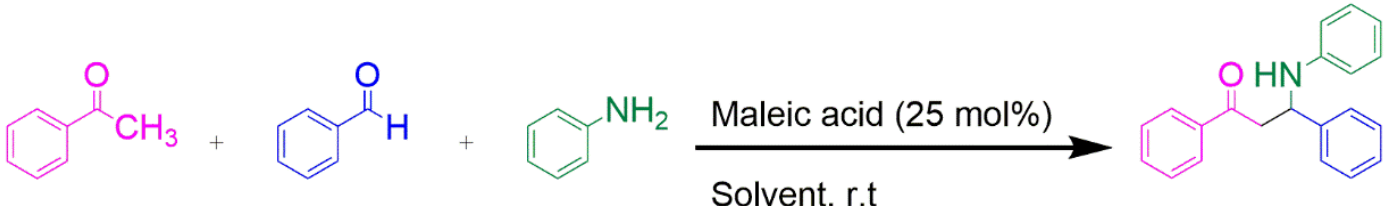
Solvent, r.t

\begin{tabular}{cccc}
$\mathbf{1}$ & $\mathbf{2}$ & & $\mathbf{4}$ \\
\hline Entry & Solvent & Time (h) & Yield (\%) $)^{\mathbf{b}}$ \\
\hline 1 & $\mathrm{H}_{2} \mathrm{O}$ & 72 & - \\
$\mathbf{2}$ & $\mathbf{E t O H}$ & $\mathbf{1 4 : 3 0}$ & $\mathbf{8 3}$ \\
3 & $\mathrm{EtOH} / \mathrm{H}_{2} \mathrm{O}(2: 1)$ & 20 & 46 \\
4 & $\mathrm{EtOH} / \mathrm{H}_{2} \mathrm{O}(1: 1)$ & 30 & 46 \\
5 & $\mathrm{EtOH} / \mathrm{H}_{2} \mathrm{O}(1: 2)$ & 72 & - \\
6 & $\mathrm{MeOH}_{2}$ & 17 & 46 \\
7 & $\mathrm{CHCl}_{3}$ & 30 & Trace \\
\hline
\end{tabular}

${ }^{\mathrm{a}}$ The reaction were carried out using acetophenone $(1 \mathrm{mmol})$, benzaldehyde $(1 \mathrm{mmol})$ and aniline $(1 \mathrm{mmol})$ in the presence of $25 \mathrm{~mol} \%$ maleic acid in various solvents at room temperature.

${ }^{\mathrm{b}}$ Isolated yield.

After the successful preparation of $\mathbf{4 b}$, we decided to introduce more diversity in the $\beta$-amino ketone scaffolds. With the optimized reaction conditions in hand, the scope of application of this three-component reaction was examined using different aldehydes, anilines and acetophenones as staring materials. Clearly, these reactions proceeded very cleanly under mild reaction conditions and no byproducts were observed. It is worthwhile to mention that 
aromatic rings in starting materials with electron-donating and electron-withdrawing groups afforded the correspond products in moderate to good yields. The results are summarized in Table 4.

Table 4. Synthesis of $\beta$-amino carbonyls 4a-o.

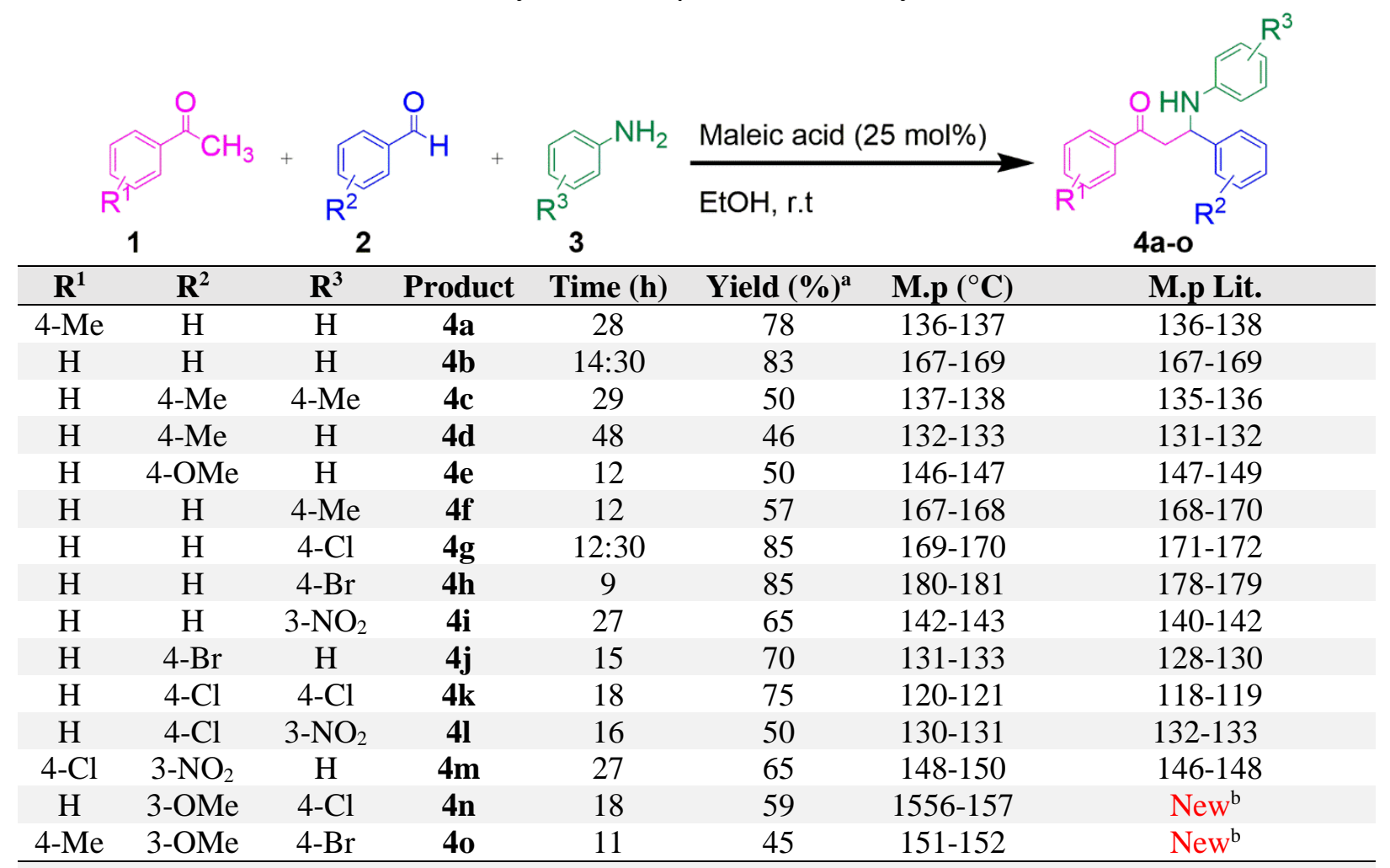

${ }^{\text {a }}$ Isolated yield.

${ }^{\mathrm{b}}$ The new compounds synthesized in this work.

The structure of all known synthesized compounds according to this procedure were characterized by comparison of the melting points and the analytical data with those reported for authentic samples. The structure of the new synthesized $\beta$-amino ketones $\mathbf{4}$ is in full agreement with ${ }^{1} \mathrm{H}$ NMR, ${ }^{13} \mathrm{C}$ NMR and elemental analysis as illustrated below for a representative example (compound 4o). The IR spectrum of $4 \mathbf{o}$ displayed a sharp peak at 3380 $\mathrm{cm}^{-1}$ was due to $\mathrm{NH}$ and one sharp strong absorption band was observed at approximately $1665 \mathrm{~cm}^{-1}$ for $\mathrm{C}=\mathrm{O}$ stretching. The ${ }^{1} \mathrm{H}$ NMR spectrum contained a characteristic single peak at $\delta=2.42 \mathrm{ppm}(\mathrm{s}, 3 \mathrm{H})$ for $\mathrm{CH}_{3}$. A doublet of doublet was assigned at $\delta=3.36 \mathrm{ppm}(J=16.0$, $7.6 \mathrm{~Hz})$ for one of the methylene protons $(\mathrm{H}-2)$. The another methylene proton of $4 \mathbf{0}\left(\mathrm{H}^{\prime}-2\right)$ was observed as a doublet of doublet at $\delta=3.45 \mathrm{ppm}(J=16.0,5.2 \mathrm{~Hz})$. A singlet was appeared at $\delta=3.97 \mathrm{ppm}(\mathrm{s}, 3 \mathrm{H})$ for $\mathrm{OCH}_{3}$. Also, a characteristic single peak was observed at $\delta=4.63 \mathrm{ppm}(\mathrm{s}, 1 \mathrm{H})$ for $\mathrm{NH}$. A doublet of doublet was assigned at $\delta=4.89 \mathrm{ppm}(J=7.2,5.2$ $\mathrm{Hz}$ ) for methine proton (H-3) (Fig. 2). The aromatic protons resonance were observed as several doublet at $\delta=6.44-7.82 \mathrm{ppm} .{ }^{13} \mathrm{C}$ NMR spectrum of 40 was exhabited a peak at $\delta=$ $197.9 \mathrm{ppm}$ for carbon of carbonyl group that is agreement with the structure of $\beta$-amino carbonyl 4o.

In analogy with reported mechanisms (YUE et al., 2009; LU and CAI, 2010; SHARMA et al., 2012; MOUSAVI et al., 2013), the following mechanism is proposed to explain the formation of product (Scheme 2). Maleic acid acts as an acid catalyst and facilitates the respective formation of imine (6) from aldehyde (2) and aniline (3) via removal of the water molecule. The next step of mechanism is the formation of enol (7) from acetophenone (1) in 
the presence of catalyst. Next, inter-molecular Mannich type reaction occur between (6) and (7) to yield the product $\beta$-amino ketones (4).

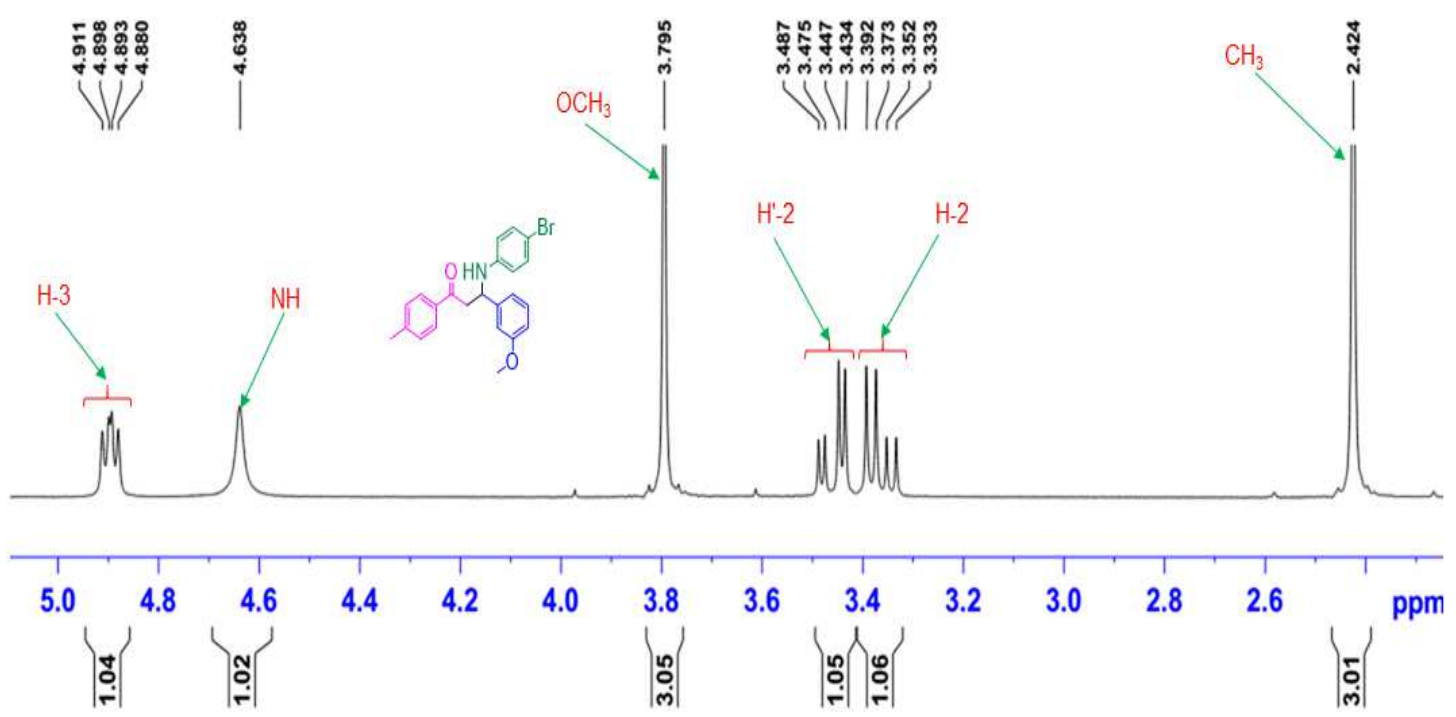

Figure 2. ${ }^{1} \mathrm{H}-\mathrm{NMR}$ of $\mathbf{4 o}$.

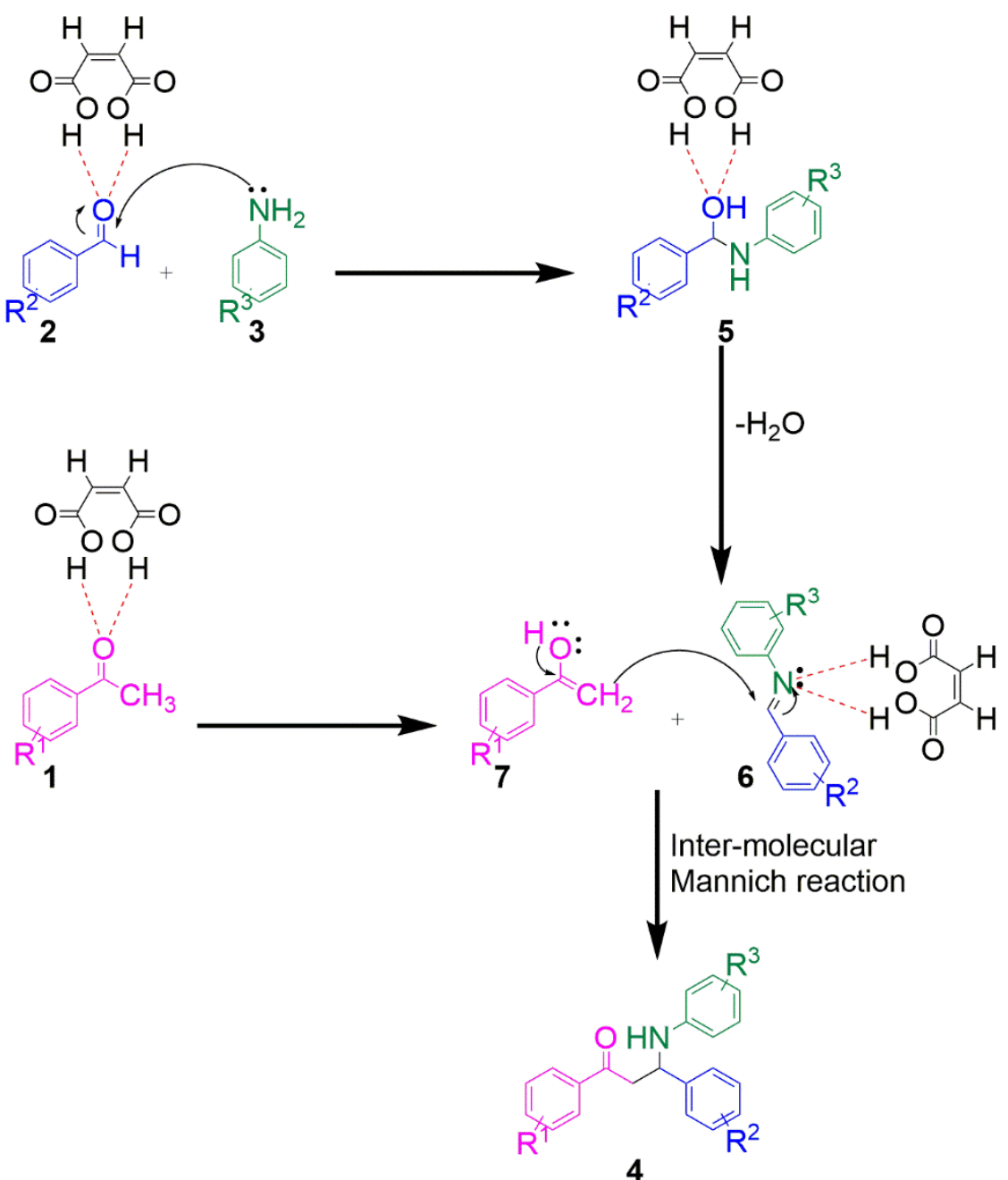

Scheme 2. Plausible mechanism for one pot synthesis of $\beta$-amino ketone. 


\section{CONCLUSION}

In summary, we have established effective and practical one-pot protocol for the synthesis of $\beta$-amino ketones by treatment of aromatic aldehydes, aromatic anilines with acetophenones in the presence of maleic acid as catalyst. The use of maleic acid in these MCRs has benefits such as clean reaction profiles, lack of side reactions, green properties, minimization of waste, a simple experimental procedure, high yields, simplicity of operation, and easy work-up. Moreover, all products were obtained through simple filtration with no need for column chromatography, which reduces the waste as well as environmental pollution.

\section{Acknowledgments}

The authors are pleased to acknowledge the financial support from University of Sistan and Bluchestan.

\section{References:}

[1] Ahmadi, T., Ziarani, G.M., Gholamzadeh, P., Mollabagher, H. (2017): Recent advances in asymmetric multicomponent reactions (AMCRs). Tetrahedron: Asymmetry 28 (5): 708-724. doi: 10.1016/j.tetasy.2017.04.002

[2] Arend, M., Westermann, B., Risch, N. (1998): Modern variants of the Mannich reaction. Angewandte Chemie International Edition 37 (8): 1044-1070.

[3] Choudhary, D., Paul, S., Gupta, R., Clark, J.H. (2006): Catalytic properties of several palladium complexes covalently anchored onto silica for the aerobic oxidation of alcohols. Green Chemistry 8 (5): 479-482. doi: 10.1039/B601363E

[4] D’SouZA, D.M., Mueller, T.J.J. (2007): Multi-component syntheses of heterocycles by transition-metal catalysis. Chemical Society Reviews 36 (7): 1095-1108. doi: $10.1039 / \mathrm{b} 608235 \mathrm{c}$

[5] DAI, Y., LI, B.D., QUAN, H.D., LÜ, C.X. (2010): $\mathrm{CeCl}_{3} .7 \mathrm{H}_{2} \mathrm{O}$ as an efficient catalyst for one-pot synthesis of $\beta$-amino ketones by three-component Mannich reaction. Chinese Chemical Letters 21 (1): 31-34. doi: 10.1016/j.cclet.2009.08.011

[6] Dömling, A., Ugi, I. (2000): Multicomponent reactions with isocyanides. Angewandte Chemie International Edition 39 (18): 3168-3210.

doi: 10.1002/1521-3773(20000915)39:18<3168::AID-ANIE3168>3.0.CO;2-U

[7] Guo, Q.-X., Liu, H., Guo, C., LuO, S.-W., Gu, Y., Gong, L.-Z. (2007): Chiral Brønsted acid-catalyzed direct asymmetric Mannich reaction. Journal of the American Chemical Society 129 (13): 3790-3791. doi: 10.1021/ja068236b

[8] Howard, N., Abell, C., Blakemore, W., Chessari, G., Congreve, M., Howard, S., Jhoti, H., Murray, C.W., Seavers, L.C.A., van MontFort, R.L.M. (2006): Application of fragment screening and fragment linking to the discovery of novel thrombin inhibitors. Journal of medicinal chemistry 49 (4): 1346-1355. doi: $10.1021 / \mathrm{jm} 050850 \mathrm{v}$ 
[9] Idhayadhulla, A., Kumar, R.S., Nasser, A.J.A., Manilal, A. (2011): Synthesis and antimicrobial activity of some new mannich base derivatives. Journal of Chemical and Pharmaceutical Research 3 (4): 904-911.

[10] Kidwai, M., Mishra, N.K., Bansal, V., Kumar, A., Mozumdar, S. (2009): Novel onepot $\mathrm{Cu}$-nanoparticles-catalyzed Mannich reaction. Tetrahedron Letters 50 (12): 13551358. doi: 10.1016/j.tetlet.2009.01.031

[11] Kobayashi, S., Ishitani, H. (1999): Catalytic enantioselective addition to imines. Chemical Reviews 99 (5): 1069-1094. doi: 10.1021/cr980414z

[12] Kobayashi, S., Manabe, K. (2002): Development of novel Lewis acid catalysts for selective organic reactions in aqueous media. Accounts of chemical research 35 (4): 209-217. doi: 10.1021/ar000145a

[13] Kureshy, R.I., Agrawal, S., Saravanan, S., Noor-Ul, H.K., Shah, A.K., Abdi, S.H.R., BAJAJ, H.C., SuRESH, E. (2010): Direct Mannich reaction mediated by $\mathrm{Fe}(\mathrm{Cp})_{2} \mathrm{PF}_{6}$ under solvent-free conditions. Tetrahedron Letters 51 (3): 489-494. doi: 10.1016/j.tetlet.2009.11.022

[14] Li, Z., MA, X., LiU, J., FenG, X., Tian, G., ZhU, A. (2007): Silica-supported aluminum chloride: A recyclable and reusable catalyst for one-pot three-component Mannich-type reactions. Journal of Molecular Catalysis A: Chemical 272 (1): 132-135. doi: 10.1016/j.molcata.2007.03.029

[15] LOH, T.-P., LIUNG, S.B.K.W., TAN, K.-L., WEI, L.-L. (2000): Three component synthesis of $\beta$-amino carbonyl compounds using indium trichloride-catalyzed one-pot Mannichtype reaction in water. Tetrahedron 56 (20): 3227-3237. doi: 10.1016/S00404020(00)00221-0

[16] LU, G., CAI, C. (2010): Mannich reactions catalyzed by perchloric acid in Triton X10 aqueous micelles. Catalysis Communications 11 (8): 745-748.

doi: 10.1016/j.catcom.2010.02.007

[17] Maddila, S., Gorle, S., Shabalala, S., Oyetade, O., Maddila, S.N., Lavanya, P., JoNNALAGADDA, S.B. (2016): Ultrasound mediated green synthesis of pyrano [2,3-c] pyrazoles by using $\mathrm{Mn}$ doped $\mathrm{ZrO}_{2}$. Arabian Journal of Chemistry. doi: 10.1016/j.arabjc.2016.04.016

[18] Maghsoodlou, M.T., Khorshidi, N., Mousavi, M.R., Hazeri, N., HabibiKHORASSANI, S.M. (2015): Starch solution as an efficient and environment-friendly catalyst for one-pot synthesis of $\beta$-aminoketones and 2,3-dihydroquinazolin-4(1H)-ones in EtOH. Research on Chemical Intermediates 41 (10): 7497-7508. doi: $10.1007 / \mathrm{s} 11164-014-1839-7$

[19] Mahrwald, R. (2013): Organocatalytic methods for C-C bond formation. Drug Discovery Today: Technologies 10 (1): e29-e36. doi: 10.1016/j.ddtec.2012.08.001

[20] Mansoor, S.S., Aswin, K., LogaiYa, K., Sudhan, S.P.N. (2015): An efficient synthesis of $\beta$-amino ketone compounds through one-pot three-component Mannich-type reactions using bismuth nitrate as catalyst. Journal of Saudi Chemical Society 19 (4): 379-386. doi: 10.1016/j.jscs.2012.04.008

[21] Mousavi, M.R., Maghsoodlou, M.T., Habibi-Khorassani, S.M. (2014): One-pot diastreoselective synthesis of highly functionalized cyclohexenones: 2-oxo-N,4,6triarylcyclohex-3-enecarboxamides. Molecular Diversity 18 (4): 821-828. doi: 10.1007/s11030-014-9541-7 
[22] Mousavi, M.R., Hazeri, N., Maghsoodlou, M.T., Salahi, S., Habibi-Khorassani, S.M. (2013): Entirely green protocol for the synthesis of $\beta$-aminoketones using saccharose as a homogenous catalyst. Chinese Chemical Letters 24 (5): 411-414. doi: 10.1016/j.cclet.2013.03.022

[23] Mousavi, M.R., Maghsoodlou, M.T. (2014): Catalytic systems containing ptoluenesulfonic acid monohydrate catalyzed the synthesis of triazoloquinazolinone and benzimidazoquinazolinone derivatives. Monatshefte für Chemie-Chemical Monthly 145 (12): 1967-1973. doi: 10.1007/s00706-014-1273-y

[24] Mousavi, M.R., Maghsoodlou, M.T. (2015): Nano-SiO 2 : a green, efficient, and reusable heterogeneous catalyst for the synthesis of quinazolinone derivatives. Journal of the Iranian Chemical Society 12 (5): 743-749. doi: 10.1007/s13738-014-0533-4

[25] Mousavi, M.R., Maghsoodlou, M.T., Hazeri, N., Aboonajmi, J., HabibiKHORASSANI, S.M. (2014): An efficient and mild procedure for the synthesis of $\beta$ aminoketones catalyzed by 2,3-dibromosuccinic acid: a new and homogenous catalyst for the Mannich reaction. Iranian Journal of Organic Chemistry 6 (3): 1323-1329.

[26] Mousavi, M.R., Maghsoodlou, M.T., HaZeri, N., Habibi-Khorassani, S.M. (2015): A simple, economical, and environmentally benign protocol for the synthesis of $[1,2,4]$ triazolo[5,1-b]quinazolin- $8(4 \mathrm{H})$-one and hexahydro[4,5]benzimidazolo[2,1b]quinazolinone derivatives. Journal of the Iranian Chemical Society 12 (8): 14191424. doi: 10.1007/s13738-015-0609-9

[27] Müller, R., Goesmann, H., Waldmann, H. (1999): N,N-Phthaloylamino acids as chiral auxiliaries in asymmetric Mannich-type reactions. Angewandte Chemie International Edition 38 (1-2): 184-187.

doi: 10.1002/(SICI)1521-3773(19990115)38:1/2<184::AID-ANIE184>3.0.CO;2-E

[28] Notz, W., Sakthivel, K., Bui, T., Zhong, G., Barbas, C.F. (2001): Amine-catalyzed direct asymmetric Mannich-type reactions. Tetrahedron Letters 42 (2): 199-201.

[29] Phukan, P., Kataki, D., Chakraborty, P. (2006): Direct synthesis of Cbz-protected $\beta$-amino ketones by iodine-catalyzed three-component condensation of aldehydes, ketones and benzyl carbamate. Tetrahedron Letters 47 (31): doi: 5523-5525. 10.1016/j.tetlet.2006.05.136

[30] Ranjbar-Karimi, R., Hashemi-UderJi, S., Mousavi, M. (2011): Selectfluor promoted environmental-friendly synthesis of $2 \mathrm{H}$-chromen-2-ones derivatives under various reaction conditions. Journal of the Iranian Chemical Society 8 (1): doi: 193-197. $10.1007 / \mathrm{BF} 03246215$

[31] Saadatjoo, N., Golshekan, M., Shariati, S., Azizi, P., Nemati, F. (2017): Ultrasound-assisted synthesis of $\beta$-amino ketones via a Mannich reaction catalyzed by $\mathrm{Fe}_{3} \mathrm{O}_{4}$ magnetite nanoparticles as an efficient, recyclable and heterogeneous catalyst. Arabian Journal of Chemistry 10 (S1): S735-S741. doi: 10.1016/j.arabjc.2012.11.018

[32] Sahoo, S., Joseph, T., Halligudi, S.B. (2006): Mannich reaction in Brönsted acidic ionic liquid: A facile synthesis of $\beta$-amino carbonyl compounds. Journal of Molecular Catalysis A: Chemical 244 (1): 179-182. doi: 10.1016/j.molcata.2005.09.012

[33] Sandaroos, R., Damavandi, S. (2013): Ultrasound-assisted one-pot synthesis of disubstituted and trisubstituted $1 \mathrm{H}$-benzo[f]chromene derivatives catalyzed by 4-nitro2,6-diacetylpyridinebis (2,4,6-trimethylaniline) $\mathrm{FeCl}_{2}$. Research on Chemical Intermediates 39 (9): 4167-4174. doi: 10.1007/s11164-012-0933-y

[34] SCHEFFLER, U., MAHRWALD, R. (2013): Recent advances in organocatalytic methods for 
asymmetric C-C bond formation. Chemistry-A European Journal 19 (43): 1434614396. doi: 10.1002/chem.201301996

[35] Sharma, R.K., Rawat, D., Gaba, G. (2012): Inorganic-organic hybrid silica based tin(II) catalyst: Synthesis, characterization and application in one-pot three-component Mannich reaction. Catalysis Communications 19: 31-36.

doi: 10.1016/j.catcom.2011.12.006

[36] Terada, M., Sorimachi, K., Uraguchi, D. (2006): Phosphorodiamidic acid as a novel structural motif of Brønsted acid catalysts for direct Mannich reaction of $\mathrm{N}$-acyl imines with 1,3-dicarbonyl compounds. Synlett 2006 (1): 133-136. doi: 0.1055/s-2005-922783

[37] Wang, L., HAN, J., Sheng, J., Tian, H., FAN, Z. (2005): Rare earth perfluorooctanoate $\left[\mathrm{RE}(\mathrm{PFO})_{3}\right]$ catalyzed one-pot Mannich reaction: three component synthesis of $\beta$-amino carbonyl compounds. Catalysis Communications 6 (3): 201-204.

doi: 10.1016/j.catcom.2004.12.009

[38] WAng, R., LI, B., HuAng, T., ShI, L., Lu, X. (2007): NbCl 5 -Catalyzed one-pot Mannichtype reaction: three component synthesis of $\beta$-amino carbonyl compounds. Tetrahedron Letters 48 (12): 2071-2073. doi: 10.1016/j.tetlet.2007.01.142

[39] WANG, X.C., ZHANG, L.J., ZHANG, Z., QuAN, Z.J. (2012): PEG-OSO 3 H as an efficient and recyclable catalyst for the synthesis of $\beta$-amino carbonyl compounds via the Mannich reaction in PEG- $\mathrm{H}_{2} \mathrm{O}$. Chinese Chemical Letters 23 (4): 423-426. doi: 10.1016/j.cclet.2012.01.016

[40] Wu, M., JING, H., ChAng, T. (2007): Synthesis of $\beta$-amino carbonyl compounds via a Mannich reaction catalyzed by SalenZn complex. Catalysis Communications 8 (12): 2217-2221. doi: 10.1016/j.catcom.2007.05.011

[41] YI, W.-B., CAI, C. (2006): Mannich-type reactions of aromatic aldehydes, anilines, and methyl ketones in fluorous biphase systems created by rare earth (III) perfluorooctane sulfonates catalysts in fluorous media. Journal of fluorine chemistry 127 (11): 15151521. doi: 10.1016/j.jfluchem.2006.07.009

[42] YUE, C.B., YI, T.F., ZHU, C.B., LIU, G. (2009): Mannich reaction catalyzed by a novel catalyst under solvent-free conditions. Journal of Industrial and Engineering Chemistry 15 (5): 653-656. doi: 10.1016/j.jiec.2009.09.038

[43] Zhang, M., Xiong, B., Yang, W., Chen, L., Wu, F., Wang, Q., Ding, Y. (2012): Highly efficient one-pot, three-component synthesis of $\beta$-aminoketones catalyzed by $\mathrm{Fe}\left(\mathrm{O}_{2} \mathrm{CCF}_{3}\right)_{3}$. Synthetic Communications 42 (19): 2831-2843.

doi: 10.1080/00397911.2011.569866 